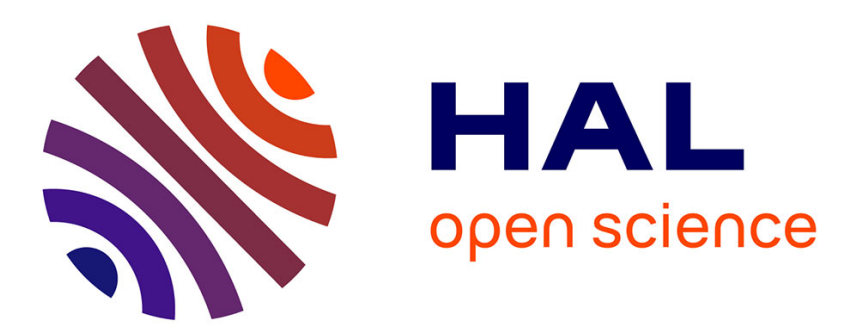

\title{
Real-Time Web-Based Decision Support for Stakeholder Implementation of Basin-Scale Salinity Management
} Nigel Quinn, Brian Hughes, Amye Osti, Joel Herr, Elwood Raley, Jun Wang

\section{To cite this version:}

Nigel Quinn, Brian Hughes, Amye Osti, Joel Herr, Elwood Raley, et al.. Real-Time Web-Based Decision Support for Stakeholder Implementation of Basin-Scale Salinity Management. 12th International Symposium on Environmental Software Systems (ISESS), May 2017, Zadar, Croatia. pp.3-18, 10.1007/978-3-319-89935-0_1 . hal-01852609

\section{HAL Id: hal-01852609 \\ https://hal.inria.fr/hal-01852609}

Submitted on 2 Aug 2018

HAL is a multi-disciplinary open access archive for the deposit and dissemination of scientific research documents, whether they are published or not. The documents may come from teaching and research institutions in France or abroad, or from public or private research centers.
L'archive ouverte pluridisciplinaire HAL, est destinée au dépôt et à la diffusion de documents scientifiques de niveau recherche, publiés ou non, émanant des établissements d'enseignement et de recherche français ou étrangers, des laboratoires publics ou privés. 


\title{
Real-time Web-based Decision Support for Stakeholder Implementation of Basin-scale Salinity Management
}

\author{
Nigel W.T. Quinn ${ }^{1}$, Brian Hughes ${ }^{4}$,Amye Osti² ${ }^{2}$ Joel Herr ${ }^{3}$, \\ Elwood Raley ${ }^{4}$, Jun Wang ${ }^{4}$ \\ ${ }^{1}$ Lawrence Berkeley National Laboratory, Berkeley, CA, USA. \\ nwquinn@lbl.gov
}

\begin{abstract}
Real-time salinity management increases annual average salt export from the agriculture-dominated and salt-impacted San Joaquin Basin. This strategy also reduces the likelihood of potential fines associated with exceedences of monthly and annual salt load allocations which could exceed \$1 million per year based on average year hydrology and State-mandated, TMDL-based salt load export limits. The essential components of this program include the establishment of telemetered sensor networks, a web-based information system for sharing data, a basin-scale salt load assimilative capacity forecasting model and institutional entities tasked with performing weekly forecasts of River salt assimilative capacity and coordinating westside drainage return flows. San Joaquin River (SJRRTM) Online (SJRO) is a new web portal that combines WARMF-Online a dedicated web portal for sharing model input data and salt assimilative capacity forecasts with an informational website for increasing stakeholder awareness of the unique characteristics and opportunities for enhanced water and water quality resource management in the River Basin.
\end{abstract}

Keywords: salinity, TMDL, decision support, forecast, web-based.

\section{Introduction}

In the USA, the Total Mass Daily Load (TMDL) is a policy instrument, developed by the US Environmental Protection Agency (EPA) for attaining compliance with water quality objectives for pollutants of concern for receiving waters (CEPA, 2002; CRWQCB, 2004a, 2004b). A unique provision in the published salinity TMDL for the San Joaquin River Basin (SJRB) was the admission of a "real-time" management salt load control strategy which substituted the attainment of a 30-day running average pollutant (salt) concentration for the typical load-based salt load allocations developed for watershed sub-basins upstream of the compliance monitoring point on the San Joaquin River (SJR). This strategy increases potential management flexibility for agricultural, wetland and municipal dischargers to the River and provides an opportunity to maxim-

adfa, p. 1, 2011.

(C) Springer-Verlag Berlin Heidelberg 2011 
ize salt load export from the Basin without exceeding environmental objectives - however it assumes a level of coordination and cooperation amongst stakeholders that does not currently exist. The core requirements of this program include: the development of a basin-scale, sensor network to collect real-time monitoring of flow and salinity data; an information dissemination system for effective sharing of data among basin stakeholders; a calibrated simulation model of hydrology and salinity in the SJR and its contributing watersheds to allow forecasting and daily assessment of River assimilative capacity (Figure 1); the development of a stakeholder-based institutional entity responsible for coordinating salinity management actions and ensuring compliance with State salinity objectives; and finally the sanction of the Central Valley Regional Water Quality Control Board (CRWQCB). Not only could successful matching of salt load export with River salt load assimilative capacity permit greater export of salt load from the watershed during normal and wet years (Quinn and Karkoski, 1998; Quinn and Hanna, 2003; Quinn et al., 2005; Quinn, 2009; Quinn et al., 2011) it would also help to overcome salt accumulation in the shallow groundwater system which would ultimately degrade the groundwater resource within the Basin. The combination of real-time monitoring, simulation modeling and forecasting of SJR assimilative capacity has the potential to optimize use of available River salt assimilative capacity, generated by releases of high quality Sierran water, which provides dilution to saline west-side agricultural and managed wetland return flows. However there needs to be coordination and sufficient lead time to allow entities being asked to charge drainage practices or alter reservoir release patterns to be able to respond. Agricultural return flows and salt loads are highest during the summer irrigation season whereas return flows and salt loads from seasonally managed wetlands are highest during the spring months of March and April, when most seasonal wetland ponds are drained to promote establishment of moist soil plants and habitat for waterfowl. These anticipated hydrologic patterns help to screen the array of practices on both the east and west sides of the Basin that will be most effective at managing salinity.

Given the uncertainty associated with estimates of salt assimilative capacity, the need for adequate lead time for stakeholders to adjust tributary inflow and drainage return flow schedules and the fact that most weather forecasts provided by news organizations rarely extend beyond two weeks - a two week forecast period and one week hindcast period was chosen for the real-time salinity management program (RTSMP). The one week hindcast refers to the technique of beginning the simulation one week in arrears so that the first week of the forecast can be compared to observed flow and electrical conductivity (EC) data. Model parameters affecting River and tributary inflow and water quality such as the partitioning coefficients that allocate watershed runoff and deep percolation to groundwater can be adjusted to recalibrate the model during periods when model output and River observations diverge. Stakeholders have embraced the suggested two-week forecast and one-week hindcast periods. 


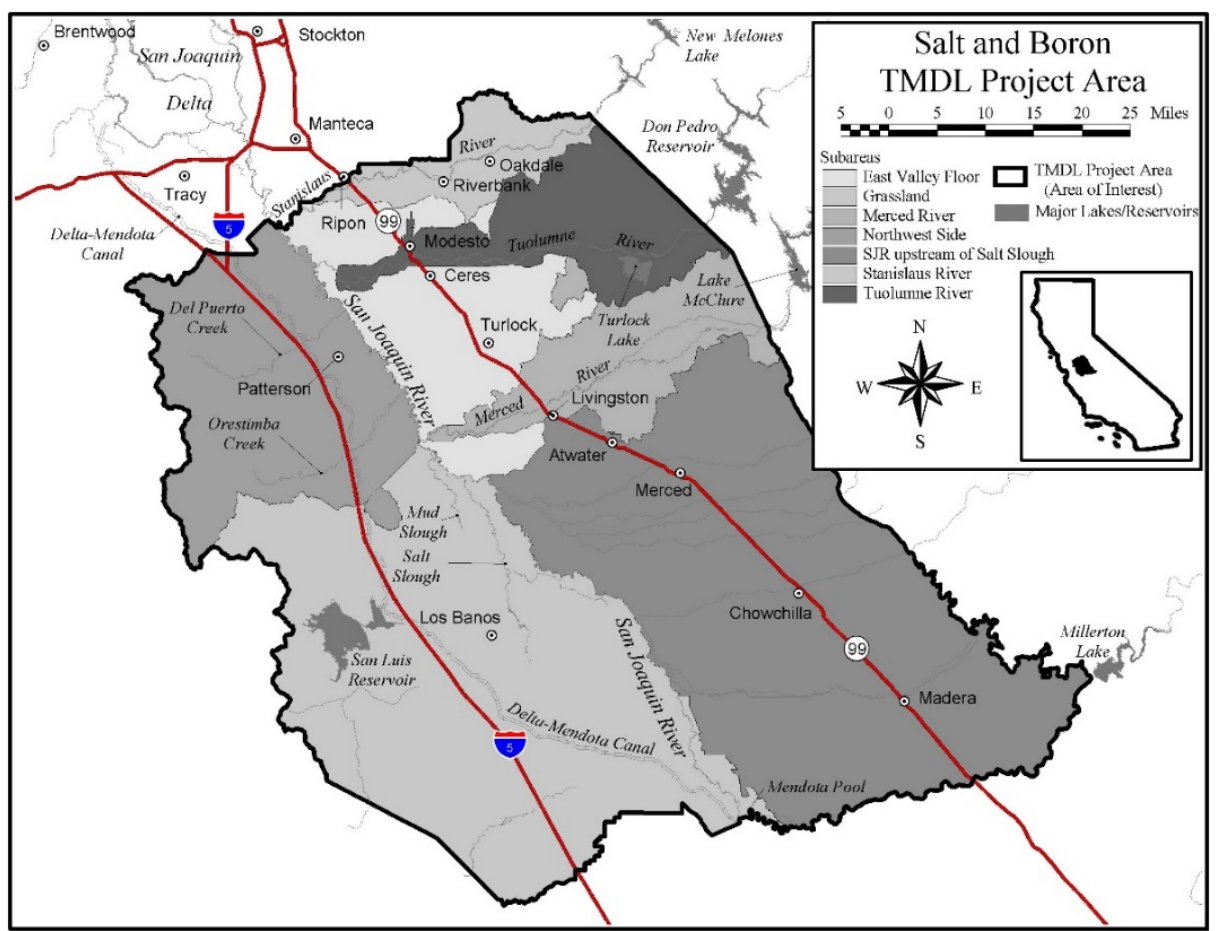

Figure 1. Subareas within the San Joaquin River Basin draining to the San Joaquin River defined in the salinity TMDL (CRWQCB, 2002).

\section{Real-time Salinity Management}

\subsection{Monitoring Networks - Data Measurement and Telemetry}

The monitoring of flow and electrical conductivity (EC) at seven purpose-built monitoring stations along the SJR and from its major east-side and west-side tributaries is undertaken mostly by water agencies such as the California Department of Water Resources (CDWR) and the US Geological Survey (USGS). These stations include the current salinity compliance station at Vernalis on the San Joaquin River, the current upstream boundary monitoring station at Lander Avenue, two major salt load conveyances from the west-side that account for up to $65 \%$ of the annual salt load to the River and three major east-side tributaries - the Stanislaus, Tuolumne and Merced River's that receive releases of most Sierra water from eastside reservoirs. Most of these stations have more than 20 years of flow and EC monitoring records and are maintained monthly. The complementary San Joaquin River Restoration Program(SJRRP) is a comprehensive long-term effort to restore a self-sustaining Chinook salmon fishery in 
the San Joaquin River from Friant Dam to the confluence of Merced River, Full restoration flows began on January 1, 2014 and the previously dry sections of the River are now permanently re-wetted. Full merger of the current RTSMP with the .SJRRP will add five or more River monitoring stations to the current sensor network and will enhance the reliability of model simulation of upper boundary inflow. Water districts and local agencies are responsible for flow and salinity monitoring within the watersheds, some of which directly discharges to the San Joaquin River. Critical data on SJR diversions is currently only collected for the major westside SJR diverters - however this data is not reported on a real-time basis. Recent California legislation requires estimation and reporting of SJR diversions by all riparians with an established right to SJR water supply. This new policy directive has provided an opportunity to coordinate and improve the reporting of stakeholder diversion data using a common reporting protocol. For the three largest diverters on the westside of the SJR this will require creating external ftp-accessible directories, firewalled from each water districts main server, that can be polled and the data contents uploaded to a single dataserver supporting the forecasting model.

A variety of telemetry technologies are used to transmit data from monitoring stations to the end user including CDMA cellular phone, GOES satellite and RF radio. State and federal agencies such as the CDWR and the USGS report real-time data to publicly available sites such as the California Data Exchange (CDEC) and the National Water Information system (NWIS) respectively - whereas most irrigation districts utilize SCADA-based monitoring networks which are private and require username and password access. One of the challenges of developing a basin wide real-time salinity management system is accessing and operationalizing these data in a timely manner that supports daily decision making while maintaining database autonomy and data security.

\subsection{Data Quality Control and Assurance}

Although data quality assurance protocols for discrete environmental sampling are well established and data quality control plans are necessary functions of all hydrologic and water quality monitoring projects - there has been incentive to integrate these activities to promote uniformity and coherence. For continuously recorded and reported data, the protocols for monitoring site visitation, rating procedures, data management, data processing and error correction are often inconsistent leading to a reluctance for stakeholders to share or rely on each other's data. Established software tools used by local water districts (WISKI) the CDWR (HYDSTRA) and the USGS (AQUARIUS) facilitate and guide these tasks that use QA data to error-correct and apply averaging techniques to continuous records. However the response time is currently insufficient to support daily forecast model runs with QA-censored data. In the case of CDWR a separate division is tasked with developing the agency-published time series data which occurs 6-12 
months after data acquisition by CDEC. The USGS has a similar turn-around time for published data on their agency NWIS website. All data prior to being published is labelled "Preliminary". In the project we strive to produce a reliable data record that can be publicly shared and readily utilized in the salt assimilative capacity forecasting model. For forecasting purposes we seek daily mean data for flow, electrical conductivity (EC) and temperature (used to make corrections to EC which is temperature dependent) that has undergone at least a preliminary level of data quality assurance. Inaccurate or absurd data posted to a project website can cause irreparable harm by producing erroneous model simulations and forecasts that can quickly lead to a loss of confidence within the stakeholder community. Since four stakeholder entities have already adopted the (Kisters Inc.,2013) WISKI hydrological data management toolbox and the CDWR uses its sister product HYDSTRA we resolved to encourage more widespread use of this common IT platform as a means of fostering the collaboration and data sharing activities required under the RTMP. The WISKI platform is capable of a large number of data quality assurance operations - the most important for our purposes are the screening and removal of values that exceed normal upper and lower threshold values or that exhibit a rate of change between readings that cause the readings to be flagged (in the watershed abrupt changes in flow and EC are not typically observed and are considered aberrant). The software is able to interpolate missing values using a variety of linear and non-linear algorithms including cubic splines which pass through control points. A similar technique is also deployed to perform data shifts that allow real-time data to be fitted to flow and EC sensor quality assurance data, performed monthly in the case of the water agencies and weekly by water districts such as Grassland Water District.

\section{Flow/water Quality Modeling, Simulation and Forecasting}

The Watershed Management Framework (WARMF) model (Herr et al., 2001; Chen et al., 2001, Herr and Chen, 2006) is comprehensive decision support tool specifically designed to facilitate TMDL development at the watershed-level. The WARMF-SJR application simulates the hydrology of entire San Joaquin River Basin which is drained by the SJR - the model performs mass balances for a broad suite of potential contaminants including total dissolved solids. The model, whose simulation domain is shown in Figure 2, simulates tributary inflows from the major east-side rivers, agricultural and wetland drainage return flows, accretions from shallow groundwater, riparian and appropriative diversions and uses hydrologic routing to calculate flow and water quality at approximately $1.6 \mathrm{~km}$ intervals along the main stem of the SJR. Wetland drainage from the Grassland Ecological Area is partitioned into component State, Federal and private wetland subarea watershed contributors to SJR salt load. 
A GIS-based model graphical user interface (GUI) facilitates the visualization of model input flow and water quality data. Although data templates are built-in to expedite automated data retrieval from State and Federal agency hydrology and water quality databases to facilitate the automated updating of model input files we opted to utilize the OpenNRM engine (described later) to facilitate this retrieval for both the model and the SJRO web portal to avoid potential inconsistencies. Water managers can enter daily schedules of diversions and discharges using a customized spreadsheet-like data interface that is also operationalized through OpenNRM. Standardized model output graphics aid the dissemination of flow and water quality forecasts exported to the dedicated WARMF-Online web portal are now part of the combined SJRO web portal. What makes the new SJRO web portal unique is the integration of real-time watershed data and model-generated flow, salinity and salt load assimilative capacity forecasts.

The RTSMP serves a diverse stakeholder community consisting of agricultural, wetland and municipal entities. The agricultural community comprises more than 40 individual water districts which exhibit their own distinct diversity among the 7 geographic subareas previously identified (Figure 1) that also generally define: (a) native

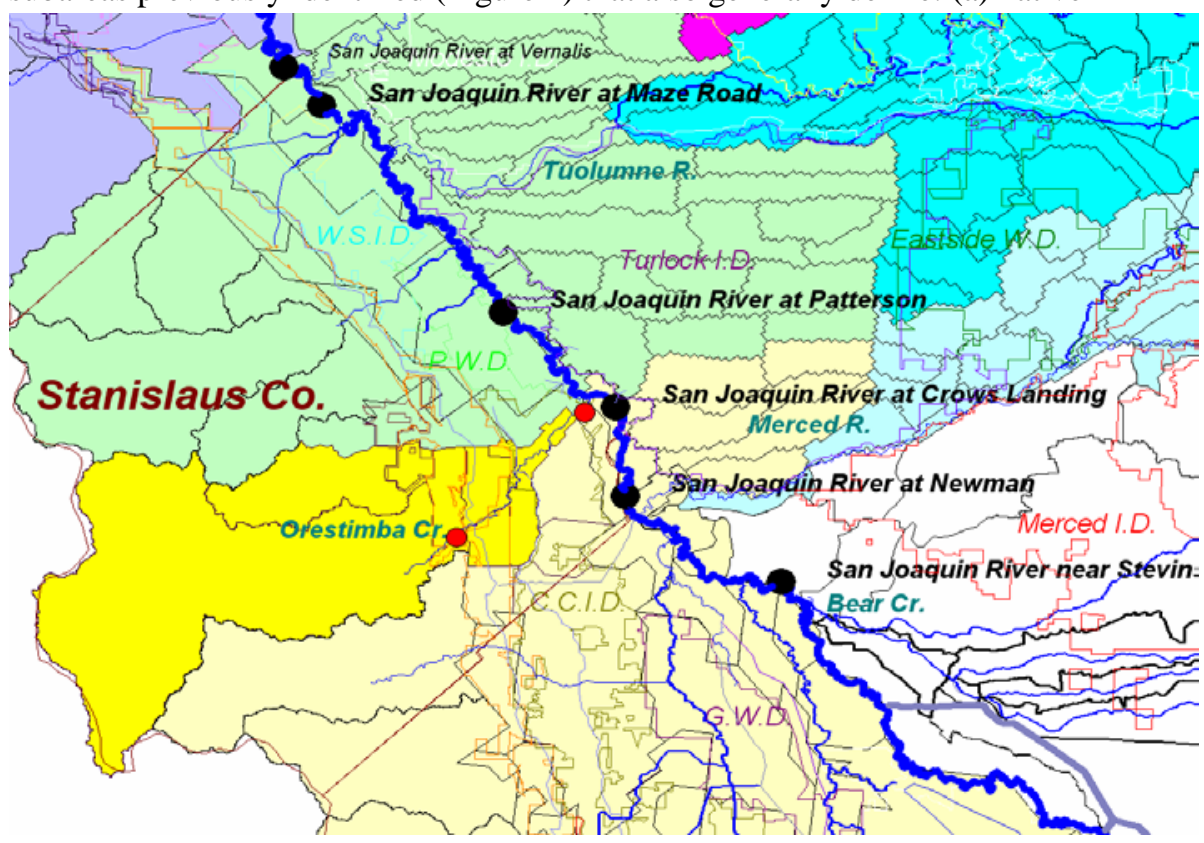

Figure 2. The WARMF-SJR model interface showing the disaggregation of watersheds contributing flow and salt load to the San Joaquin River into component drainages. The hydrology of the San Joaquin Basin is such that the political boundaries of individual agricultural water districts are the most appropriate primary unit (sub-watershed) for monitoring, management and control of salt loading to the San Joaquin River from the west-side. Sub-watersheds on the east-side of the San Joaquin River are determined by the irrigation supply and surface drainage network. 
soil salinity; (b) irrigation supply water quality; (c) drainage relief with respect to proximity to the San Joaquin River; and institutional support within stakeholder-led coalitions. The eastside water districts are larger, wealthier with greater resources all of which serve both agricultural and municipal customers. Since the source of their water supply is the Sierra-Nevada mountains water quantity and electrical power rather than water quality have been the major focus of District activities. Because do not divert water from the SJR they are less impacted by salinity and have been more challenging to "bring-to-the-table" for real-time data coordination activities in support of the WARMF-SJR salt assimilative capacity forecast modeling. The westside divided into Grasslands and Northwest side subareas are distinguished from each other primarily by the higher concentration of native salts and the diminished reliance on SJR diversions as a source of irrigation water supply in the Grasslands subarea.

Outreach to westside agricultural stakeholders has concentrated on familiarizing farmers and water district managers with the concept of salt load assimilative capacity and how it varies with season and by water year type. These stakeholders have a wellevolved skepticism of models and model-based analyses and an important aspect of outreach has been the simultaneous display of model flow, EC and salt load assimilative capacity forecasts and real-time observations, as shown in an example (Figure 3), to incrementally build trust in the ability of the model to simulate ambient conditions. Discussion in open forums of WARMF-SJR based salt assimilative capacity forecasts are also used as a vehicle to encourage greater stakeholder engagement including sharing of real-time drainage discharge and River diversion information. We have demonstrated, during stakeholder presentations, the significance of errors that can occur, especially during dry and critically dry years, when default model diversion data (nine year averaged daily mean) are used in-lieu of actual data from westside riparian diverters. The threat of having inaccurate data associated with two of the three major westside riparian diverters has been effective in catalyzing initial data transfer of historic daily diversion data from these water districts.

The wetland entities that form the 140,000 acre (64,000 ha) Grassland Ecological Area (GEA) similarly exhibit their own unique diversity largely on account of their institutional status as State and Federal wildlife refuges on one hand and privately owned duck clubs (some that combine cattle grazing) on the other. Habitat objectives dictate the fall wetland flood-up schedule and more importantly the spring wetland drawdown period. Discharges of salt load between late February and the end of April each year coincide with agricultural pre-irrigation - problematic for those agricultural stakeholders that divert the majority of their water supply from the San Joaquin River. Coordination of salt load discharge schedules for the GEA is being undertaken by the Grassland Water District that has been the first to embrace the concept of RTSM largely on account of being able to use the same sensor network of 50 flow and EC stations for both water conservation and salinity management purposes. We have found that technology transfer and embrace of web-based sensor technologies occurs faster 
and more effectively between stakeholders facing similar problems than from vendors of technical experts in water agencies.
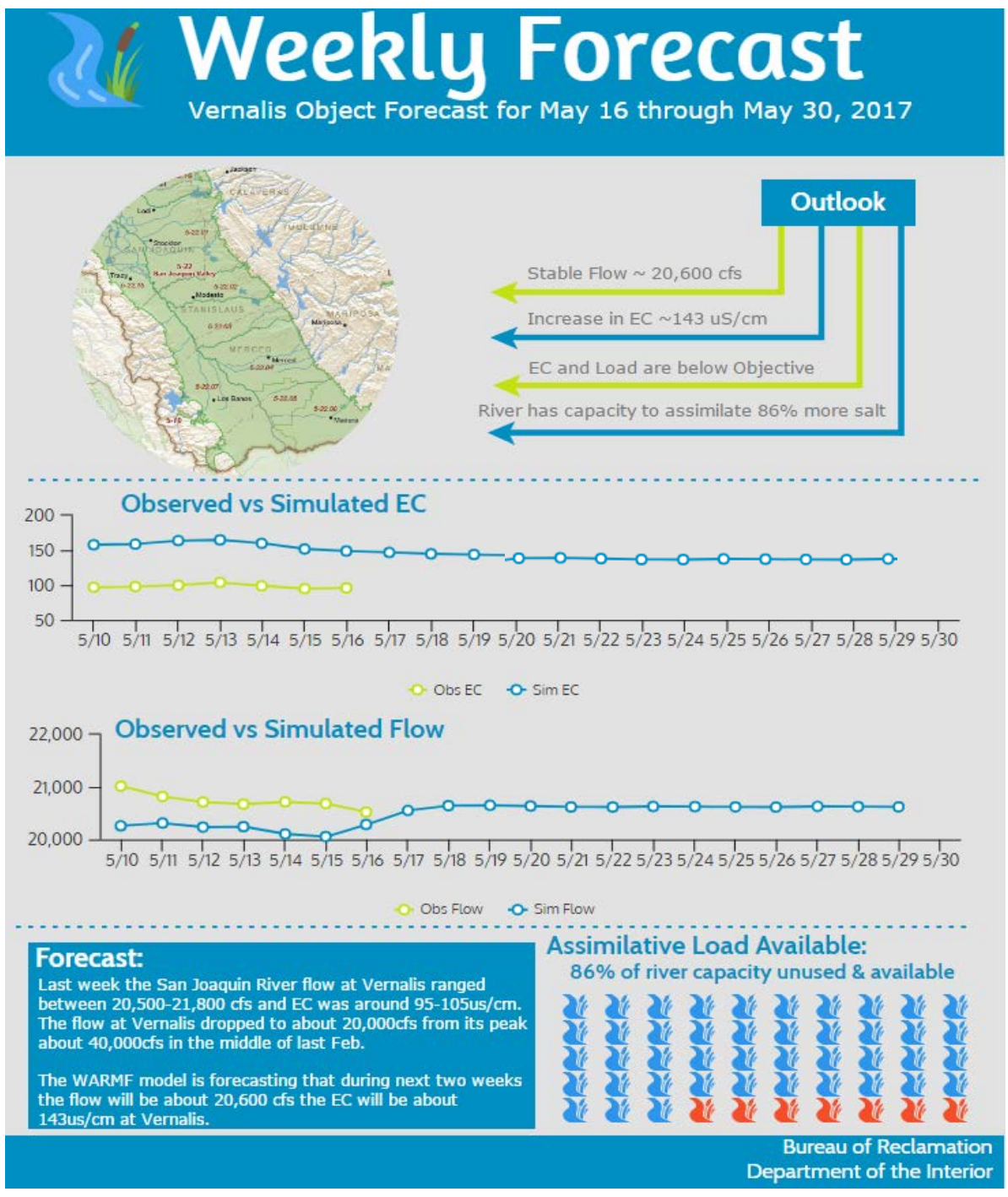

Figure 3. Prototype WARMF-SJR model-based forecast graphic being used to encourage stakeholder interest and engagement in RTSMP activities. Given the newness of the concept of RTSM - stakeholders do not necessarily know a-priori their preferences for data visualization and quantitative representation of the concept of salt load assimilative capacity. The WARMF-Online web portal is being developed through feedback at scheduled stakeholder meetings. 


\section{Web-based Decision Support}

\subsection{Collaborative Resource Management System for Data Visualization, Analysis and Decision Support}

Collaborative, real-time salinity management (RTSM) is best facilitated when all stakeholders have a forum and toolset for aggregating and accessing the data and information used to inform management decisions and operations. The SJR RTMP has developed a comprehensive resource (San Joaquin River Real Time Management - (SJRRTM) Online (abbreviated to San Joaquin River Online-SJRO) that combines WARMFOnline - the dedicated web portal for sharing model input data and salt assimilative capacity forecasts (Figures 4 and 5) - with an informational website for increasing stakeholder awareness of the unique characteristics and opportunities for enhanced

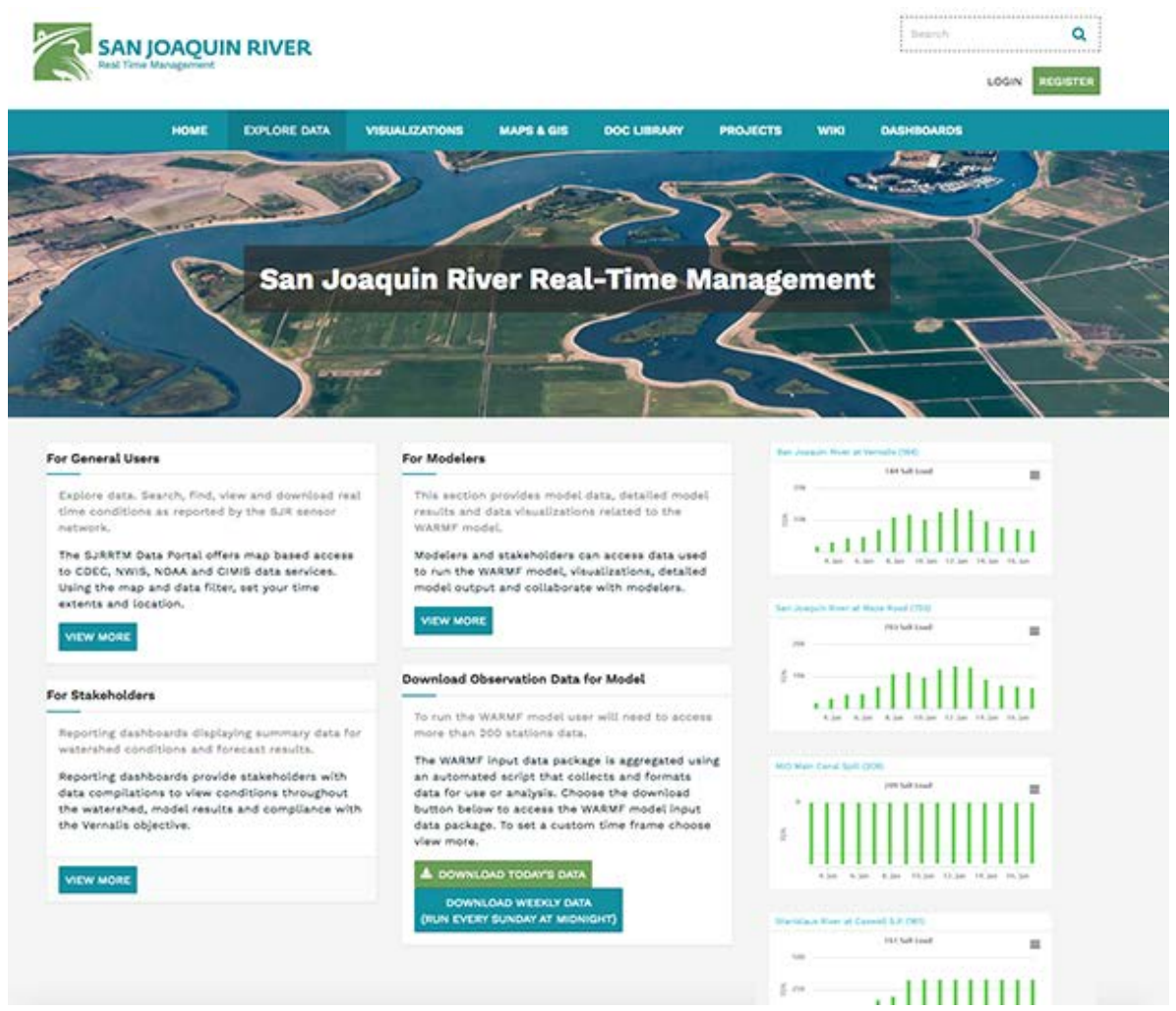

Figure 4. San Joaquin River (SJRRTM) Online (SJRO) web portal using the OpenNRM visualization toolbox. The web portal provides data access to visualizations of WARMF-SJR model output. The model provides forecasts for weekly salt assimilative capacity and GIS-based data analysis. 


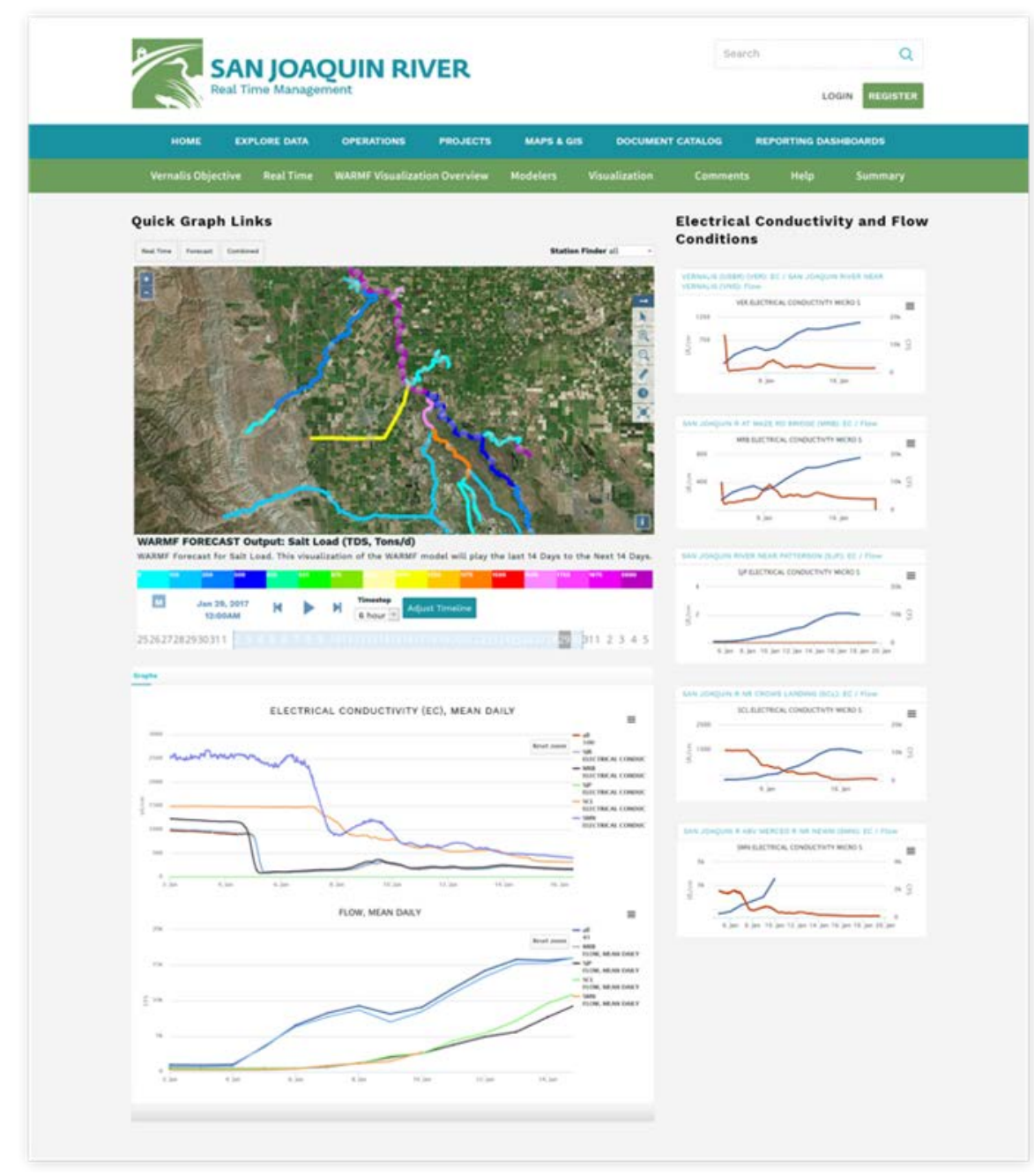

Figure 5. Visualization of WARMF-SJR model results in SJRO - published daily for collaborative viewing of forecasted conditions of the River and its tributaries in the Basin. Visualizations are supported with additional analytics for comparing observed and forecasted data. The web portal provides data access to more than 365 monitoring sites throughout the basin. Reporting dashboards are in real time and can be compared with modeled data.

water and water quality resource management in the River Basin. SJRO supports collaborative efforts to improve salinity management in the San Joaquin River and gives stakeholders access to resources (reports, GIS, datasets), reporting dashboards for viewing WARMF model output and supplemental data as well as a collaborative workspace 
for evaluating and discussing system conditions. SJRO aims to provide stakeholders with timely information and a transparent process for coordinating system-wide salt loading schedules with reservoir releases of high quality flows from the East-side of the Basin. The web based data management platform OpenNRM, is a Collaborative Natural Resource Management software tool developed by 34-North Inc. in concert with the project team.

OpenNRM allows users to create, modify and manage data and content collectively and provides filtering capability to parse information based on regions, areas of responsibility, hot spots, presets and more using mapping and data dashboard interfaces. Geocoded information is enabled for all data types extending the map and dashboards to include document libraries, projects databases, datasets, visualizations, wiki knowledge bases, publications and miscellaneous file types related to specific locations. The framework supports simple and robust construction of dashboards, common operating pictures, adaptive management scenarios, regional management cyberinfrastructure, workspaces and project collaboration tools.

OpenNRM is currently implemented as five hosted open data management platforms throughout the State of California. This open data federation approach provides instant access to State and Nationwide datasets and services including the California Irrigation Management System (CIMIS), California Data Exchange (CDEC), National Water Information System (NWIS), National Oceanic Atmospheric, Administration (NOAA), water quality databases including STREAMWATCH, CEDEN, STORET and hundreds of GIS Layers. CIMIS, CDEC, NWIS and NOAA provide real-time data used in the development of San Joaquin River salt assimilative capacity forecasts using the WARMF-SJR model. The OpenNRM platform has been customized to provide stakeholders with the following decision support resources and tools:

1. Data tools to visualize and analyze current watershed conditions. Baseline data and baseline conditions.

2. Data and information needed to assess future environmental conditions and support management actions using the WARMF-SJR model and real time analytics.

3. Data aggregation and formatting tools to efficiently run the WARMF-SJR model and system wide assessments. Support resources to better understand how the San Joaquin Basin functions including research catalogs, regulatory resources, interactive maps, real time data visualizations, charts and graphs.

4. OpenNRM also addresses the need for a collaborative workspace for supporting, organizing, managing, analyzing, visualizing, archiving and reporting project and operations information.

5. The creation of SJRO facilitates analysis, synthesis, assessment and communication to develop a credible process in which stakeholders can participate in order to ensure that data are appropriately assessed, interpreted, and reported. 


\subsection{Customized SJRO Features for Real Time Salinity Management}

The data aggregation toolset in SJRO prepares data packages from a variety of agencies and data sources that include approximately 356 monitoring sites (meteorological hydrologic, and water quality data) using preset and user defined time extents. The assembled data is formatted and converted to make the data compatible for import into the WARMF-SJR forecasting model as well as the online reporting dashboards and assessments. This tool also generates base line data for modelers and stakeholders running independent analytics. A second key feature is the simplification of data management and access by centralizing key datasets and management tools. To better understand the characteristic behavior of the SJRB sensor data is spatially organized using interactive maps and data dashboards allowing stakeholders to track flow, salinity, salt load export and irrigation diversions from the upper reaches of the SJR through to the Sacramento - San Joaquin Bay Delta. The data are collected from a wide range of sources and made comparable using map based data visualizations alongside interactive charts and graphs. Users can compare Electrical Conductivity (EC), River Discharge, and Salt Load from both the forecasted model output and real time observations.

Customized post-processed visual outputs such as the GOWDY Output (Figure 6) allow the user to directly access WARMF-SJR model simulation results and toggle between views of flow, EC and salt load for the entire San Joaquin River between Lander Avenue and Vernalis (a $96 \mathrm{~km}$ reach) for a single day in the year. On the left panel flows into the River show as green horizontal columns superimposed over the input source whereas diversions from the River show up as red horizontal columns to the left of zero. In the top and bottom panels to the right of the screen are shown travel time showing an initial value of 1.8 days diminishing to zero days at the Vernalis compliance monitoring station. Flow is shown increasing from left to right as the east-side tributaries discharge into the River. The lower right-hand panel shows the same cumulative flow relative to cumulative River diversions. Powerful visualization aids such as the Gowdy Output provide the user with a comprehensive daily window into the complex characteristics of flow and water quality in the San Joaquin Basin.

Although Basin stakeholders have endorsed the concept of RTSM the novelty of decision support implications of RTSM implementation are unclear to the majority of these stakeholders. Hence the primary initial goal of SJRO has been to educate stakeholders on the characteristics of the Basin, the various means of generating salt assimilative capacity within the Basin and the potential performance of various salinity management strategies (that include both incidental measures such as river diversions and drainage water reuse and deliberate strategies such as short-term ponding of drainage in small reservoirs). Other short-term goals are specific to water managers within each of the major contributing subareas to the SJR. For example west-side agricultural water districts that divert directly from the SJR for a portion of their agricultural water supply 
will be interested in assessing compliance with the newly promulgated upstream salinity objectives at the upstream Crows Landing monitoring station - which directly impacts the salinity of their River diversions. The wetland entities which include private duck clubs, State and Federal wildlife refuges will be concerned with scheduling of their annual wetland drawdown during the months of March and April so as not to exceed available River salt assimilative capacity. East-side water districts that control reservoir releases along tributaries to the SJR that generate much of the River's salt assimilative capacity will want to develop a better understanding of how to optimize the timing of these events with west-side salt loads and their own salt loading to the River and how to improve communication of these opportunities.

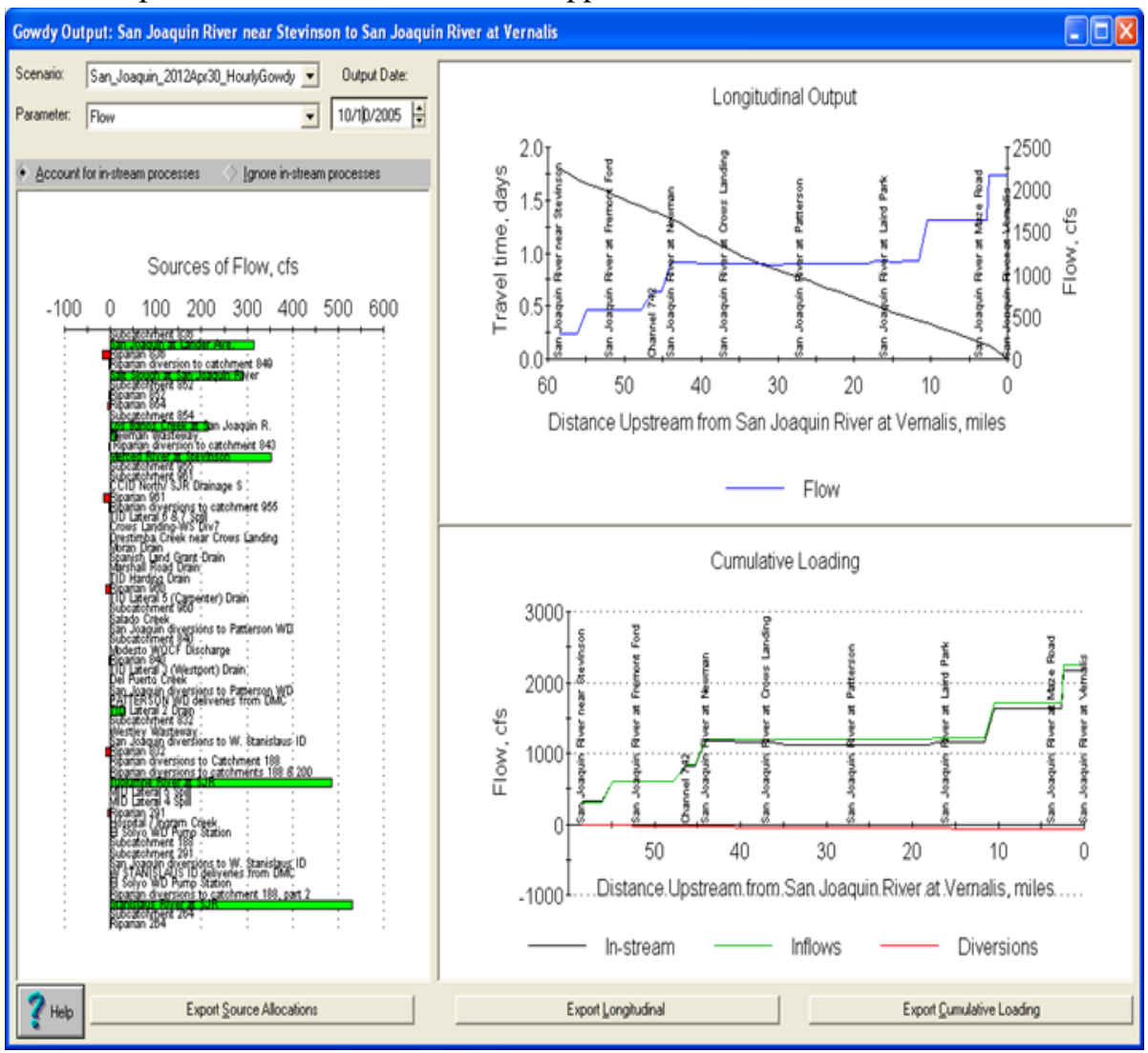

Figure 6. Gowdy customized outputs showing daily inflow and diversions every 1.6 $\mathrm{km}$ along the mainstem of the San Joaquin River for a chosen annual time series output from the WARMF-SJR simulation and forecasting model.

Data and model forecast visualization is a key component of SJRO. Model-based forecasts and simulations runs are shared and can be viewed as a recording or in video format. The OpenNRM application allows certain model outputs such as EC, flow and 
salt load to be interactive and viewed spatially on a map. Attribute tables determine how the values from surrounding monitoring stations are assigned to each watershed polygons and color coded using the OpenNRM display tools. Data is delivered using the OpenNRM content management system that ingests a binary and proprietary RIV file. The result allows the end user to see the salinity conditions over a user-specified time window - typically two weeks for the salt assimilative capacity forecast.

The SJRO visualization tools are designed so that model simulations and forecast runs can be repurposed and enhanced for additional studies or analysis. When fully implemented SJRO will supply real-time flow and salinity data from public water agency websites, cooperating water districts and other stakeholders to enable reliable daily simulations and forecasts of River assimilative capacity to the San Joaquin River. Future forecasts will utilize a single web-based version of the model application. This web based model will be continuously calibrated and upgraded with new algorithms and bug fixes. Future WARMF-SJR model forecast runs will be made by a small core group of stakeholder and/or agency personnel with write access privileges to the model. Model outputs and post-processed visualizations will continue to be made available to the public through SJRO web portal.

\subsection{Coordinated Stakeholder Decision Support for Salinity Management}

In early 2016 the San Joaquin Valley Drainage Authority (SJVDA) initiated informational quarterly stakeholder meetings on behalf of the Westside San Joaquin River Watershed Coalition (WSJRWC) on the topic of data management, data coordination and mechanisms for data sharing - a core requirement for RTSM. The WSJRWC (www.sjvdc.org) currently: (a) represents water districts and other agricultural and wetland stakeholders located within the Grassland and North-West side subregions; (b) manages data collection at a large number monitoring sites and; (c) submits reports on these data to the CVRWQCB. Similarly on the east-side of the Basin the East San Joaquin Water Quality Coalition (ESJWQC) (www.esjcoalition.org) files required monitoring reports with the CVRWQCB on behalf of its 1000+ farmers and stakeholder entities, provides conditional waiver coverage for members of the coalition, develops and is responsible for implementation of the real-time water quality monitoring program. The ESJWQC communicates and advises landowners when water quality monitoring indicates the occurrence of a problem exist and helps with the timely development of equitable solutions. Ultimately the WSJRWC and the ESJWQC will need to develop a Memorandum of Understanding for joint implementation of the real-time management program recognizing the use of the WARMF-SJR model as a decisionmaking tool to forecast availability of River assimilative capacity. Realization of the potential of RTSM may require the formation of a basin-scale salinity management entity built upon the WSJRWC and the ESJWQC with the authority to encourage compliance with sub-basin salt load targets through incentives or penalties set at mutually 
agreed-upon salinity compliance monitoring locations.

In Figure 7 a simplified workflow, feedback and control schema is shown that provides an overview of the current institutional decision support framework. Weekly salt load forecasts will be made for each of the seven subareas and compared to salt load allocations for these same subareas determined using the procedures published in the Water Quality Basin Plan for the San Joaquin Basin.

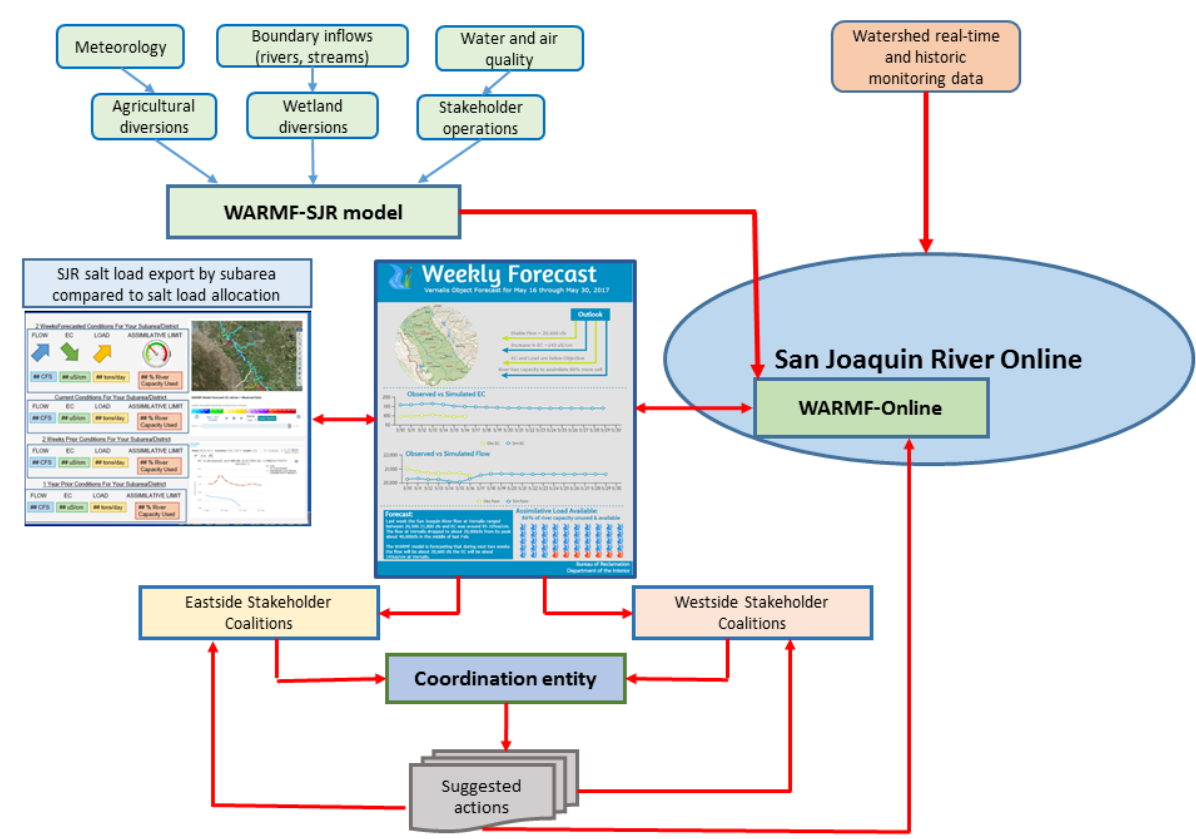

Figure 7. Process workflow showing the main steps in developing weekly salt load assimilative capacity forecasts and the role of the coordination entity in allocating resources to improve San Joaquin River salinity during periods of exceedence.

The salt load allocation procedures are based on current flow conditions and subtract background salt loading, groundwater accretions and point source load allocations from River assimilative capacity (estimated by multiplying the same flow condition by the salinity compliance objective at the Vernalis monitoring station). It is assumed that only $85 \%$ of the available assimilative capacity is available - hence a factor of safety of $15 \%$ is applied to each salt load allocation for each of the seven contributing subareas. While salinity objectives are being met at Vernalis no action is required to control and make scheduling adjustments to salt export to the River. However at times, such as during dry or critically dry years, when the objective might be violated - those subareas not in 
compliance would be obligated to reduce salt export or enter a salt load trading arrangement with compliant subareas to bring the entire system into compliance.

Following the schema in Figure 7 - real-time watershed data used by the WARMFSJR model to develop weekly forecasts are compared with subarea salt load allocations using the same flow and EC predictions provide by the model and reviewed by the separate eastside and westside stakeholder coalitions. The (as yet un-named) coordination entity would be responsible for managing salt export in those subareas in instances where the model-based forecasts suggested a potential future violation. During the past decade there have been less than five violations of the Vernalis objective that would have required action by stakeholders that might invite complacency. However the Regional Water Quality Control Board requirements for real-time salinity management require that a response program be ready and implementable if stakeholders are to continue to enjoy the economic and environmental benefits of being part of the Program. The Board can impose a fine of up to $\$ 5,000$ per day to any Subarea within the basin that is found in violation of Subarea salt load limits during any period of violation of the Vernalis salinity objective.

\section{$5 \quad$ Summary and Conclusions}

Technical advances in data acquisition and information dissemination technologies have made possible the initial stages of implementation of a real-time salinity management program in California's SJRB. Experience to date with respect to implementation of RTSM in the San Joaquin Basin suggests the following principles moving forward, that have been discussed in the paper: (a) necessary stakeholder participation in the design and operation of existing and planned flow and water quality monitoring stations and web-based IT solutions that provide easy access to the real-time data being collected; (b) decision support system enhancement that utilizes technical expertise within the WSJRWC and ESJWQC and works toward implementation of a common system; (c) WARMF-SJR simulation model enhancements with full GIS capabilities and made more robust in its ability retrieve real-time data through the current WARMF-Online and SJRO web browsing tools. A state-of-the-art visualization engine with imaginative graphics to enhance stakeholder understanding of the current system and how their actions can impact salt load export; (d) more widespread support for data quality assurance technologies such as WISKI and HYDSTRA to improve accuracy of the real-time data being utilized by the WARMF-SJR forecasting model and reduce the fear of posting erroneous data; (e) greater automation of the process of providing salt assimilative capacity forecasts and an eventual transition from weekly to daily forecasts which allow feedbacks between stakeholder actions that update the state of the system; (f) institutional arrangements that formalize and streamline salt loading trading between subareas within the eastside and westside stakeholder coalitions that minimize institutional oversight and remedy potential salinity compliance violations before they occur.. 
The process of implementing RTSM in the SJRB will further encourage innovation - successful implementation will have significant transfer value to other highly regulated river basins where water quality is a concern.

Acknowledgements. The authors acknowledge support from the US Bureau of Reclamation that has financed development of the essential tools for RTSM implementation.

\section{References}

1. California Environmental Protection Agency (2002) Total Maximum Daily Load for Salinity and Boron in the Lower San Joaquin River. Staff report by the Regional Water Quality Control Board, Central Valley Region.

2. California Regional Water Quality Control Board (2004a) Amendments to the Water Quality Control Plan for the Sacramento River and San Joaquin River Basin. Draft Final Staff Report and Technical TMDL Report, Sacramento, CA.

3. Central Valley Regional Water Quality Control Board (2004b) Technical TMDL Report for Salt and Boron in the Lower San Joaquin River Appendix 1. July 2004 Draft Final Report.

4. Chen, C.W., J. Herr, and L.H.Z. Weintraub (2001) Watershed Analysis Risk Management Framework: Update One: A Decision Support System for Watershed Analysis and Total Maximum Daily Load Calculation, Allocation, and Implementation. EPRI, Palo Alto, CA. Topical Report 1005181.

5. Chen, C.W., J. Herr, L.E. Gomez, N.W.T. Quinn, J. Kipps, P.J. Landis, and E.W. Cummings (1996) Design and Development of a Graphic User Interface for Real-Time Water Quality Management of the San Joaquin River. Prepared for California Department of Water Resources, San Joaquin District, California..

6. Herr, J., L.H.Z. Weintraub, and C.W. Chen (2001) User's Guide to WARMF: Documentation of Graphical User Interface. EPRI, Palo Alto, CA. Topical Report.

7. Herr J., and C.W. Chen (2006) San Joaquin River Model: Calibration Report. CALFED Project ERP-02D-P63 Monitoring and Investigations for the San Joaquin River and Tributaries Related to Dissolved Oxygen. Systech Water Resources Inc. San Ramon, CA.

8. KISTERS Inc. (2013) WISKI hydrological data management software. Citrus Heights, CA 95610-5800. kna@kisters.net.

9. Quinn, N.W.T. and Hanna W.M. (2003) A decision support system for adaptive real-time management of seasonal wetlands in California. Environmental Modelling and Software, Volume 18, Issue 6, pp. 503-511

10. Quinn, N.W.T. and Karkoski, J. (1998) Real-time management of water quality in the San Joaquin River Basin, California. American Water Resources Association, Vol. 34, No. 6.

11. Quinn N.W.T., Hanlon J.S., Burns J.R., Taylor C.M., Lundquist T. and Stringfellow W.T. (2005) Real-Time Water Quality Monitoring and Habitat Assessment in the San Luis National Wildlife Refuge. Lawrence Berkeley National Laboratory Topical Report \# 58813, Berkeley, CA.

12 Quinn N.W.T., Ortega R. and Holm L. (2011). Environmental sensor networks and continuous data quality assurance to manage salinity within a highly regulated river basin. 
Decision Support Systems in Agriculture, Food and the Environment: Trends, Applications and Advances.

13. Quinn N.W.T, (2009) Environmental decision support system development for seasonal wetland salt management in a river basin subjected to water quality regulation. Agricultural Water Management, 96 (2), p.247-254, Feb 2009. 